Cite this: DOI: $10.1039 / \mathrm{c0xx00000x}$

www.rsc.org/xxxxxx

ARTICLE TYPE

\title{
Intumescent multilayer hybrid coating for flame retardant cotton fabrics based on layer-by-layer assembly and sol-gel process
}

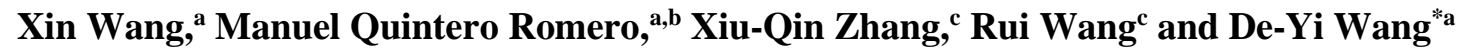 \\ Received (in $X X X, X X X)$ Xth $X X X X X X X X X 20 X X$, Accepted Xth $X X X X X X X X X 20 X X$ \\ ${ }_{5}$ DOI: 10.1039/b000000x
}

\begin{abstract}
An intumescent coating composed of nitrogen-modified silane hybrid ( $\mathrm{SiN}$ ) and phytic acid (PA) was deposited on cotton fabric through layer-by-layer assembly in order to reduce flammability. SiN was synthesized via sol-gel process and characterized by ${ }^{29} \mathrm{Si}$-nuclear magnetic resonance. This intumescent coating system lowered the thermal stability of the cotton due to the catalyzed effect on degradation, but

10 significantly improved the char formation. In a vertical flame test, fabrics coated with 15 bilayers (BLs) of SiN-PA extinguished the flame immediately upon removing the ignition source, while untreated cotton was completely burned out. Cone calorimeter data revealed that $15 \mathrm{BL}-$ coated cotton resulted in a $31 \%$ and $38 \%$ reduction in peak heat release rate and total heat release, respectively, relative to those of the uncoated control. This superior fire retardant performance is believed to be attributed to the formation of

15 intumescent char layer on fibers that could effectively inhibit the oxygen and heat permeation when burning. In addition, as evidenced by thermogravimetric analysis-Fourier transform infrared spectroscopy results, the increased amount of inflammable gases and the decreased amount of flammable gases during the degradation of coated cotton fabrics was another important factor to improve the flame resistance.

These results demonstrate the combination of layer-by-layer assembly and sol-gel method will provide an 20 effective alternative to current flame retardant treatments.
\end{abstract}

\section{Introduction}

The fire statistics in the past several years illustrate that fire accidents occurred in civilian homes have led to considerable fire-related fatalities and amount of property damage. ${ }^{1,2}$ Ignition 25 of household textiles is one of the most common fire reasons accounting for the residential home fires, particularly with respect to upholstery and mattresses. Therefore, various textiles fire safety regulations and legislation have been made in order to save lives and protect property. Various strategies have been 30 developed to obtain fire retardant fabrics: surface photo-induced grafting treatment, ${ }^{3}$ fire-retardant additives ${ }^{4}$ or co-monomers ${ }^{5}$ in synthetic fabrics, fiber blending, ${ }^{6}$ etc. More recently, layer-bylayer (LbL) assembly has been applied as a surface treatment to endow fabrics with flame resistance. ${ }^{1}$

35 LbL assembly is a simple and versatile method by alternately exposing a substrate to positively and negatively charged solutions that are adsorbed as nanolayers. LbL has been used as a novel flame retardant platform technology for cotton fabrics, ${ }^{1,2}$ polyester fabrics, ${ }^{7,8}$ polyamide $^{9}$ and flexible polyurethane 40 foams. ${ }^{10,11}$ Among these investigations, various polymers, colloids, or molecules have been incorporated to form the coating on the substrates.

Another effective alternative to fire protection is achieved through the sol-gel technique that leads to the formation of 45 organic-inorganic hybrid coatings. Silicon hydrogel derived from sol-gel process could provide fire protection by inorganic barrier formation (silica), demonstrating self-extinguishing behavior on cotton fabrics. ${ }^{12}$ Besides the silicon hydrogel, phosphorus- and/or nitrogen-based compounds have been exploited for flame 50 retardant treatments of fabrics through forming the intumescent char layer. ${ }^{13}$ In this way, phosphorus- and/or nitrogen-based compounds could catalyze the dehydration and carbonization of matrix, reduce the amount of combustible gases and thus improve the fire resistance. ${ }^{14}$ However, the current intumescent flame 55 retardant coatings are mostly mixture of multi-components. Integrating phosphorus-, nitrogen- and silicon-based species into one component is an interesting work.

In this work, a novel intumescent coating system was developed based on layer-by-layer assembly and sol-gel process 60 in order to improve the fire resistance of fabrics. Firstly, the nitrogen modified silicon hydrogel cationic solution was prepared through sol-gel method; subsequently, the multi-layered coating composed of nitrogen modified silicon hydrogel and phytic acid was deposited on the surface of cotton using LbL assembly. The ${ }_{65}$ fire resistance and the related mechanism were investigated by cone calorimeter and thermogravimetric analysis-infrared spectrometry technique. The work reported here will broaden the application of silicon hydrogel as a promising candidate for $\mathrm{LbL}$ assembly of flame retardant coating system.

\section{${ }_{70}$ Experimental section}

\section{Materials}


Cotton fabric with a density of $800 \mathrm{~g} \mathrm{~m}^{-2}$ was kindly supplied by Beijing Institute of Fashion Technology. 3-Aminopropyl triethoxysilane (APTES), 3-triethoxysilyl propyl isocyanate (TESPI), 1,3,5-tris(2-hydroxyethyl)isocyanurate (THEIC), phytic 5 acid (PA), hydrochloric acid (37\%) and ethanol were purchased from Sigma-Aldrich and used as received. Deionized water is used for all experiments unless otherwise stated.

\section{Preparation of cationic solution through sol-gel method}

The cationic solution for the cotton fabrics' impregnation was 10 synthesized by the sol-gel technique, as shown in Scheme 1. 0.06 mol of TESPI and $0.02 \mathrm{~mol}$ of THEIC were introduced into a three-necked round bottom flask equipped with the nitrogen inlet. Subsequently, the mixture was heated to $150{ }^{\circ} \mathrm{C}$ until THEIC totally dissolved and maintained for $5 \mathrm{~h}$ under nitrogen 15 atmosphere. A transparent and viscous intermediate named TESIC was obtained. Then, $0.02 \mathrm{~mol}$ of TES-IC and $0.02 \mathrm{~mol}$ of APTES were added into a mixture of ethanol and water $(1: 1)$ and adjusted to $\mathrm{pH} 4$ with $2 \mathrm{M}$ hydrochloric acid. The mixture was stirred for $4 \mathrm{~h}$ to allow hydrolysis and pre-condensation to form a
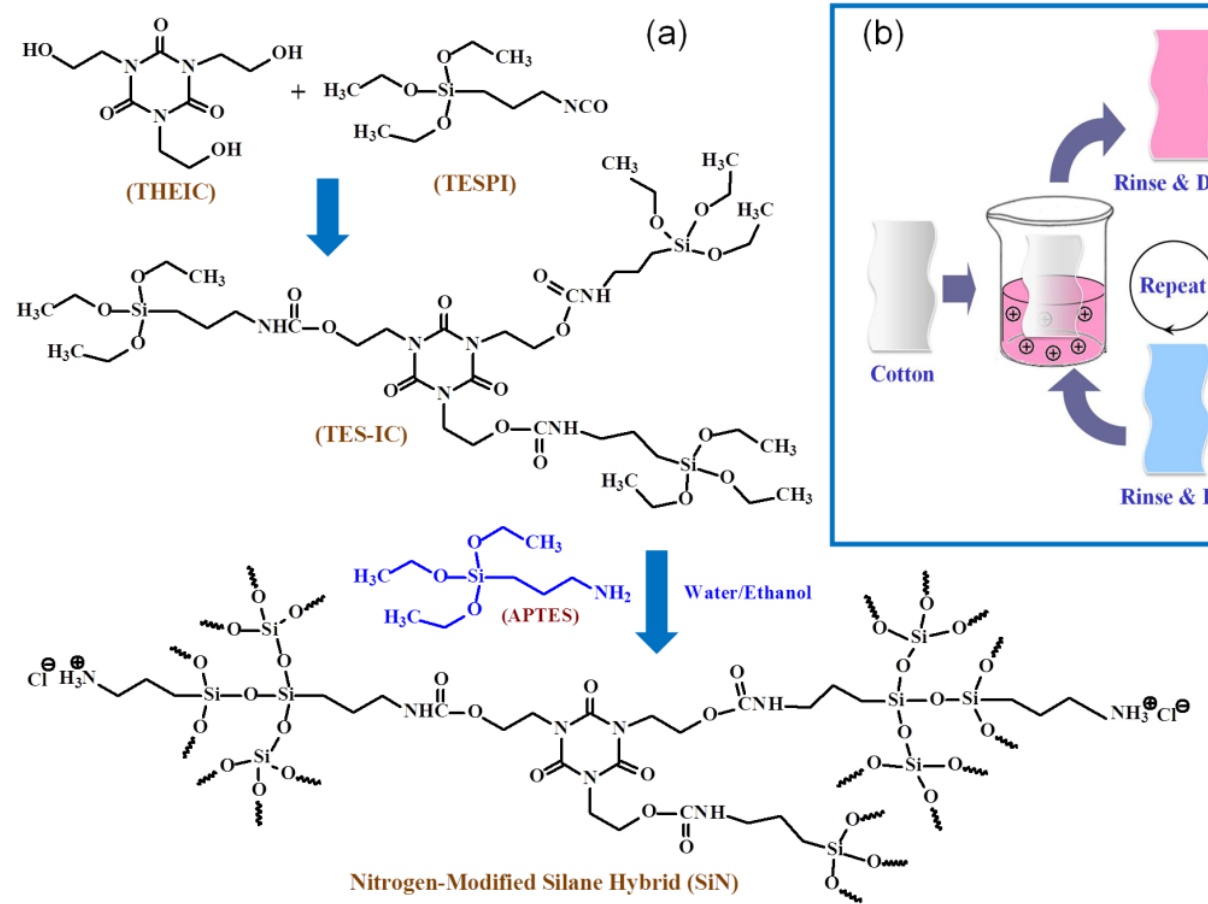

20 cationic sol named $\mathrm{SiN}$.

\section{Preparation of coated cotton fabrics by layer-by-layer technology}

The anionic medium used was $4.0 \mathrm{wt} \%$ phytic acid aqueous solution, and its $\mathrm{pH}$ was adjusted to 7 with $1 \mathrm{M} \mathrm{NaOH}$ solution 25 prior to deposition. As shown in Scheme 1, a typical sample preparation procedure was as follows: a piece of cotton fabric was first impregnated into the $4.0 \mathrm{wt} \% \mathrm{SiN}$ solution for $5 \mathrm{~min}$, washed with deionized water, squeezed out to remove excess $\mathrm{SiN}$ solution and dried with air; subsequently, the cotton fabric was 30 immersed into the $4.0 \mathrm{wt} \%$ PA solution for $5 \mathrm{~min}$, washed with deionized water, squeezed out to remove excess PA solution and dried with air. This process was a complete deposition cycle for one bilayer (BL) of SiN and PA. Such a cycle was repeated by alternately immersing cotton fabric into the cationic and anionic 35 solutions. Initial immersions were $5 \mathrm{~min}$ each, while following immersions were $1 \mathrm{~min}$. Finally, when 5, 10 and $15 \mathrm{BLs}$ of coating was deposited, fabrics were dried at $80{ }^{\circ} \mathrm{C}$ in an oven for $12 \mathrm{~h}$ before testing.

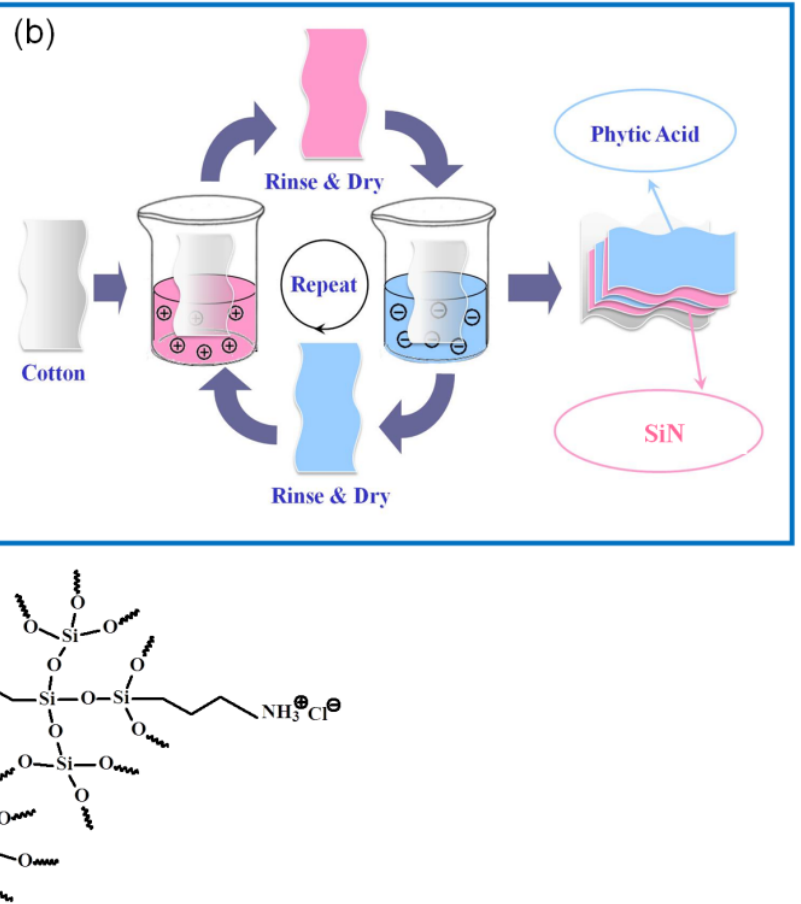

40 Scheme 1 Schematic illustration of (a) synthesis of nitrogen-modified silane hybrid; (b) layer-by-layer assembly of SiN and PA on cotton fabrics.

\section{Characterization}

${ }^{1} \mathrm{H}-,{ }^{13} \mathrm{C}$ - and ${ }^{29} \mathrm{Si}-\mathrm{NMR}$ spectra were recorded on a Bruker AVANCE-500 NMR spectrometer operating in the Fourier transform mode using DMSO- $\mathrm{d}_{6}$ as solvent. FT-IR transmittance 45 spectra were recorded using an iS50 FT-IR spectrophotometer (Nicolet Instruments, USA). The range was set from 4000 to 400 $\mathrm{cm}^{-1}$ with 16 scans and a resolution of $4 \mathrm{~cm}^{-1}$. Surface morphology of un-coated and coated cotton fabrics before and after burning was observed with a scanning electron microscopy

50 (SEM, EVO MA15, Zeiss, Germany). All the samples were coated with a conductive layer of gold prior to SEM observation. The thickness of the coating on the silicon wafer was measured by M-2000DI discrete wavelength ellipsometer (Microphotonics,
J. A. Woollam Co.) with the $\mathrm{HeNe}$ laser $(632.8 \mathrm{~nm})$. ${ }_{55}$ Thermogravimetric analysis (TGA) of the samples were performed on a Q50 thermal analyzer (TA Instruments, USA) from 30 to $700{ }^{\circ} \mathrm{C}$ at a heating rate of $20^{\circ} \mathrm{C} \mathrm{min}{ }^{-1}$ in nitrogen atmosphere. The vertical burning characteristics of the samples were measured according to ASTM D 1230-94 standard method. ${ }_{60}$ Five parallels for each sample were processed and an average of the data was used for interpretation. The burning behaviour of the samples was also evaluated using dual cone calorimeter (Fire Testing Technology, UK) according to ISO 5660. Samples with the size of $100 \times 100 \times 2 \mathrm{~mm}^{3}$ were mounted into aluminium foil 65 (with frame and grid) and irradiated horizontally at a heat flux of $35 \mathrm{~kW} \mathrm{~m}^{-2}$. Measurement was done in triplicate and the average 
data were reported. Thermogravimetric analysis-infrared spectrometry (TG-IR) was carried out on a Q50 thermal analyzer which was coupled with the iS50 FT-IR spectrophotometer through a stainless steel transfer pipe. The pipe and gas cell were

5 kept at 300 and $250{ }^{\circ} \mathrm{C}$, respectively, to avoid the condensation of the volatile products.

\section{Results and discussion}

Fig. 1 shows FTIR spectra of TESPI and TES-IC. The absorption bands at 2980 and $2870 \mathrm{~cm}^{-1}$ are attributed to the stretching 10 vibration of $-\mathrm{CH}_{3}$ and $-\mathrm{CH}_{2}-$ groups, respectively; the strong absorption band at $2270 \mathrm{~cm}^{-1}$ is assigned to -NCO group; the intense absorption band at $1088 \mathrm{~cm}^{-1}$ is ascribed to $\mathrm{Si}-\mathrm{O}-\mathrm{C}$ bond in the organo-silane. In the FTIR spectrum of TES-IC, some new characteristic bands are observed: the stretching vibrations of the ${ }_{15} \mathrm{~N}-\mathrm{H}$ groups occur at 3345 and $1530 \mathrm{~cm}^{-1}$, which together with the carbonyl bands at $1698 \mathrm{~cm}^{-1}$ are indicative of the existence of urethane moieties; the bands at $1454 \mathrm{~cm}^{-1}$ is due to the skeleton vibration of the isocyanuric ring. Additionally, the characteristic band of-NCO disappears for TES-IC, indicating the successful 20 reaction between TESPI and THEIC.

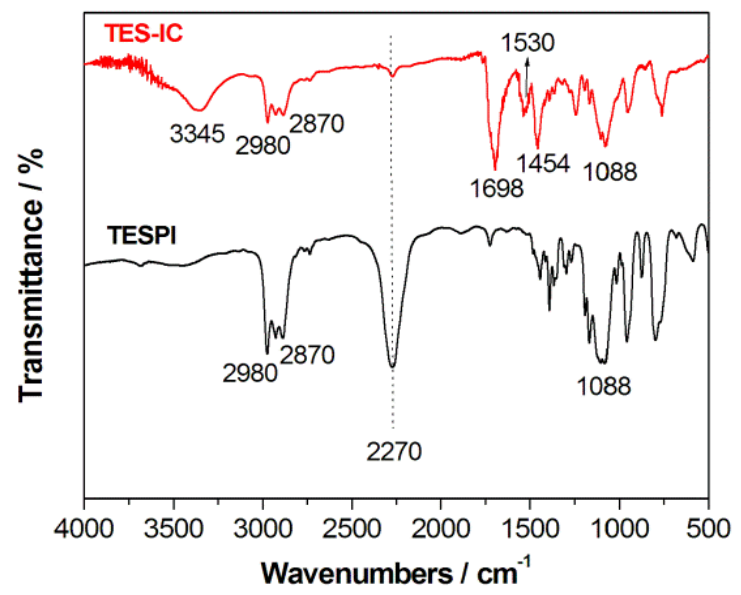

Fig. 1 FT-IR spectra of TESPI and TES-IC.

To further validate the successful occurrence of reaction between TESPI and THEIC, ${ }^{1} \mathrm{H}-\mathrm{NMR}$ and ${ }^{13} \mathrm{C}-\mathrm{NMR}$ 25 measurements are employed to characterize TES-IC, as shown in Fig. 2. Composition of TES-IC is determined by integration of ${ }^{1} \mathrm{H}-\mathrm{NMR}$ peaks at $3.9-4.1$ and $3.5 \mathrm{ppm}$ corresponding to $\mathrm{a}, \mathrm{b}$ methylenes of THEIC units, respectively, and the signal at 2.9, 1.4 and $0.5 \mathrm{ppm}$ corresponding to $\mathrm{d}$, e and $\mathrm{f}$ methylenes of TESPI 30 unit. The resonance signals at 3.7 and $1.1 \mathrm{ppm}$ is also attributed to the protons (labeled $\mathrm{g}$ and $\mathrm{h}$ ) of methylene and methyl group in the siloxane structure. Additionally, one resonance signal at 6.8 ppm (labeled c), assigned to the protons of secondary amine originated from TESPI, indicating the successful reaction 35 between TESPI and THEIC. The ${ }^{13} \mathrm{C}-\mathrm{NMR}$ signals also correspond well with the structure of TES-IC.
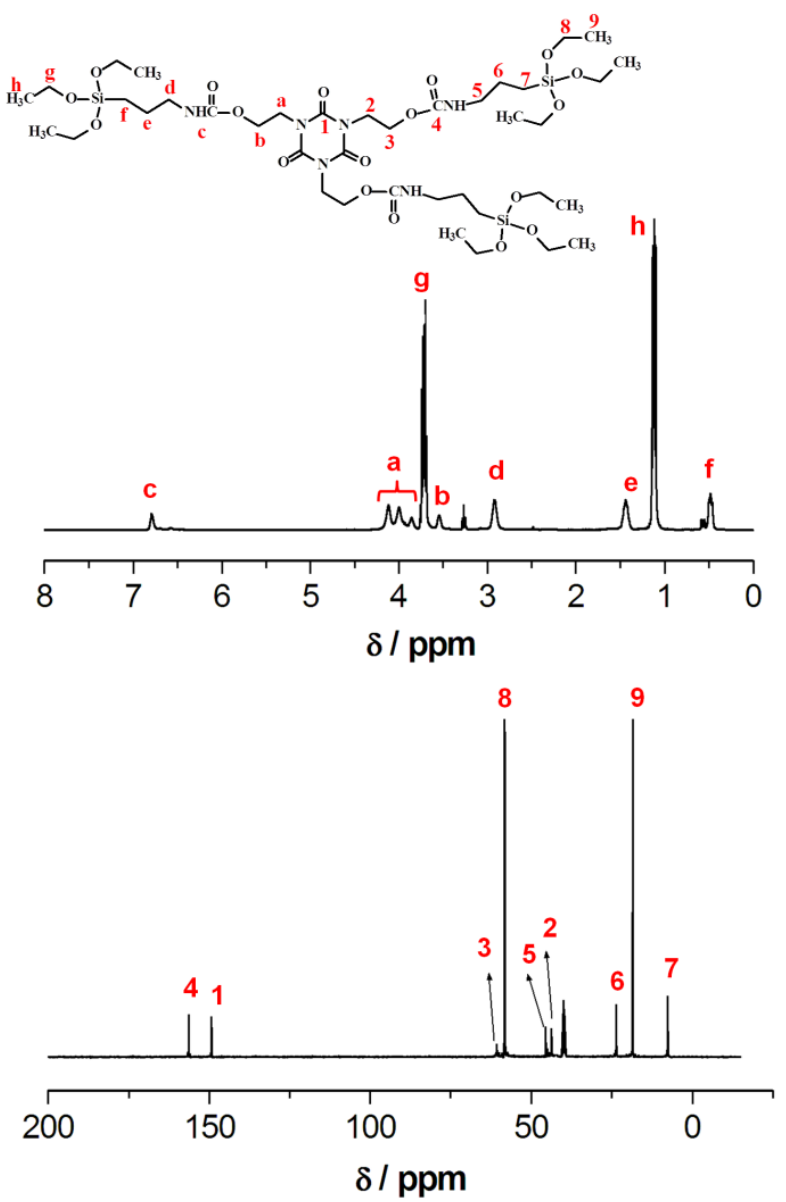

Fig. $2{ }^{1} \mathrm{H}$-NMR (top) and ${ }^{13} \mathrm{C}-\mathrm{NMR}$ (bottom) spectra of TES-IC recorded in DMSO- $\mathrm{d}_{6}$.

40 The sol-gel process was monitored by ${ }^{29} \mathrm{Si}-\mathrm{NMR}$ measurement, as shown in Fig. 3. TES-IC exhibits a single signal, indicating silicon atom only exists in one chemical environment. In contrast, the ${ }^{29} \mathrm{Si}-\mathrm{NMR}$ of SiN hybrid shows two resonance signals at -59.5 and $-68.5 \mathrm{ppm}$, which are corresponding to di-substituted (T2) 45 and tri-substituted (T3) siloxanes, respectively. ${ }^{15}$ The appearance of T2 and T3 siloxanes suggests the complete hydrolysis and condensation between TES-IC and APTES. In addition, the results reveal that $\mathrm{T} 3$ are the predominant microstructures compared to $\mathrm{T} 2$, demonstrating the formation of strongly cross${ }_{50}$ linking networks. 


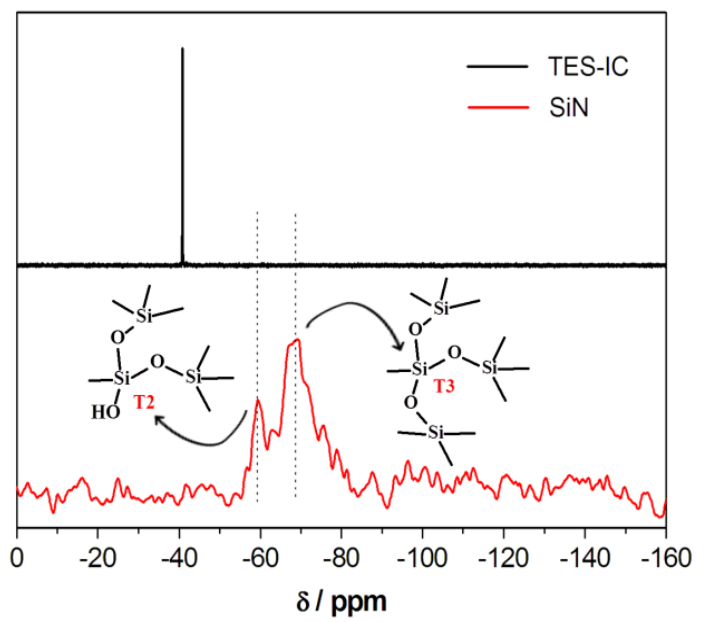

Fig. $3{ }^{29} \mathrm{Si}-\mathrm{NMR}$ spectra of TES-IC and SiN.
Scanning electron microscopy was employed to observe the morphological features of the untreated and coated cotton fabrics, 5 as shown in Fig. 4. The control fiber shows a smooth surface and 5 BL-coated cotton seems very similar in terms of fiber's structure and shape. When the BL number increases to 10 , the rougher surface can be clearly observed, which suggests that silicon-containing compounds and phytic acid have been 10 successfully deposited on the surface of the cotton. At higher magnification, some fibers appear linked together. As for $15 \mathrm{BL}-$ coated cotton, the roughness of the fibers becomes more obvious and the gaps between fibers gradually disappear due to the increased amount of coatings.
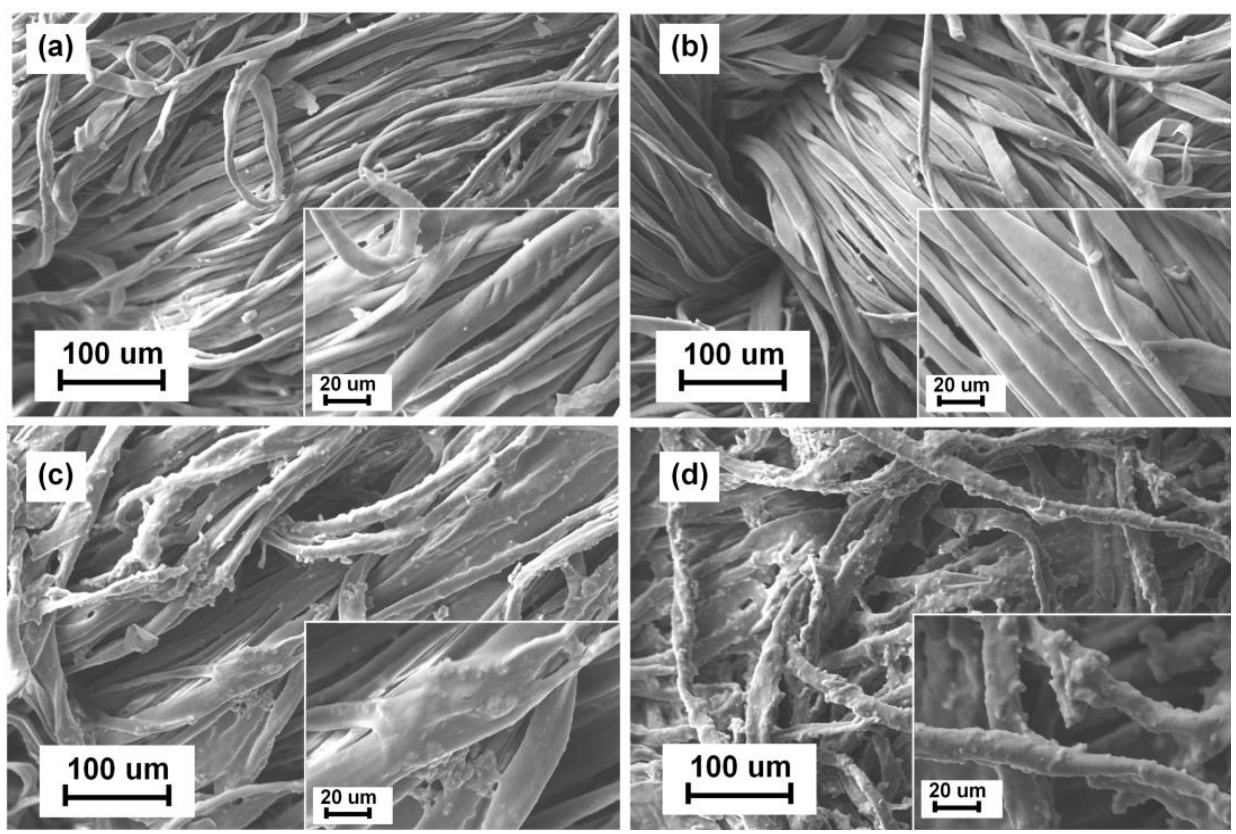

Fig. 4 SEM images of the control, cotton-5BL, cotton-10BL and cotton-15BL at different magnification.

The mass increased versus the number of bilayers plots for the coated cotton fabrics are shown in Fig. 5. It is found that 25 sequential deposition of cationic $\mathrm{SiN}$ and anionic PA on the cotton fabrics confirms the linear growth trend. The mass increased for 5, 10, and 15BL-coated cotton fabrics is $13.2 \%$, $22.1 \%$ and $31.4 \%$, respectively. SiN-PA bilayers were deposited on silicon wafers for thickness measurement. The thickness of 30 this bilayer sequence also grows linearly as a function of the number of bilayers deposited (inset of Fig. 5).

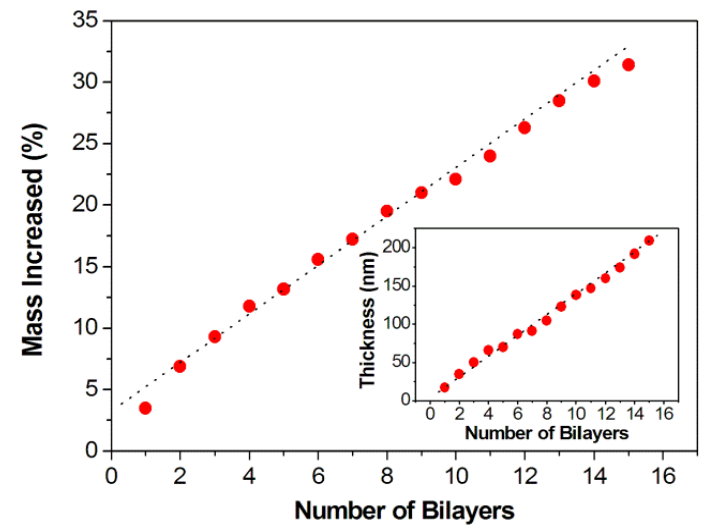

Fig. 5 Mass and film thickness (inset) as a function of the number of bilayers deposited. 
Thermogravimetric analysis was carried out to assess the thermal degradation behaviors of the untreated and coated cotton fabrics, as shown in Fig. 6. The typical degradation temperature, such as the temperature at which the mass loss is $5 \%\left(\mathrm{~T}_{5 \%}\right)$ and 5 the temperature at the maximum mass loss rate $\left(\mathrm{T}_{\max }\right)$, and the char residue percentage are summarized in Table 1. TG analysis of untreated cotton sample in nitrogen shows the onset degradation temperature at about $310^{\circ} \mathrm{C}$, accompanying with its maximum mass loss rate at about $375^{\circ} \mathrm{C}$ due to depolymerization 10 by trans-glycosylation reactions. ${ }^{16}$ The cotton fabric treated with 5 bilayers of SiN-PA coatings shows a lower onset degradation temperature, reaching the maximum mass loss rate at $343{ }^{\circ} \mathrm{C}$. The reduced thermal stability is attributed to the earlier degradation of the phosphorus-containing compounds that could catalyze the 15 decomposition of cotton to form the intumescent char. The intumescent char could shield the fabrics from flame; therefore, the lowered decomposition temperature is likely necessary rather than a defect of the system. The fabrics treated with 10 and $15 \mathrm{BL}$ of SiN-PA coatings show a similar trend with the lowered 20 degradation temperature. However, the char residue at $700{ }^{\circ} \mathrm{C}$ is improved significantly, from $4.6 \%$ (untreated cotton) to about $31.0 \%$ (cotton-5 BL), $36.1 \%$ (cotton-10 BL) or $39.9 \%$ (cotton-15 $\mathrm{BL}$ ). In addition, from DTG profiles, it can be seen that the maximum mass loss rate of SiN-PA treated cottons is much lower 25 than that of the control sample, meaning the suppressed thermal degradation process.

As is well known, the char yield reflects the flame retardancy of polymeric materials. ${ }^{17}$ In our formulations, the phosphoruscontaining compound (phytic acid) catalyzes the dehydration of 30 cellulose to form the remarkable char yield. For this reason the reduction in the onset degradation temperature facilitates the carbonaceous residue formation. The silicon-containing compounds convert into silica when burning which stabilizes the char toward the thermal degradation process, producing a higher 35 amount of char. This increased char yield serves as thermal insulating barrier that could effectively inhibit the mass and the heat transfer between the cotton and the surroundings.

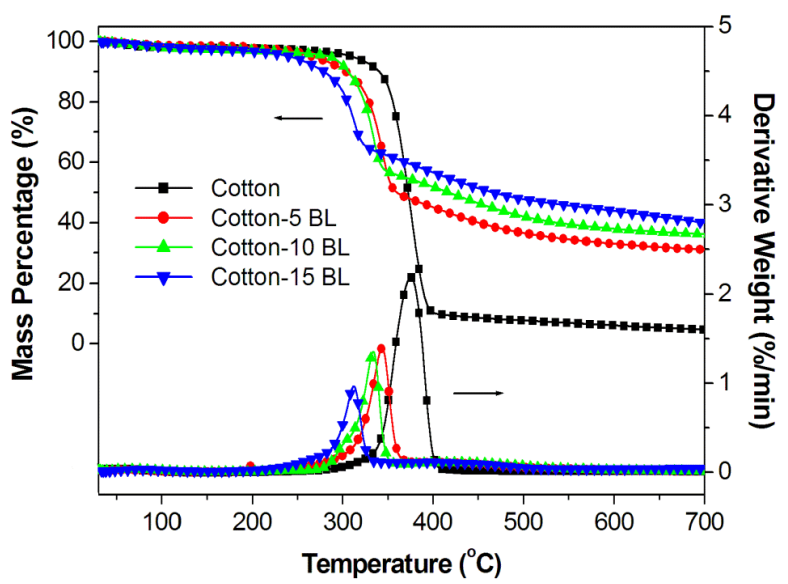

Fig. 6 TG and DTG profiles of untreated cotton and coated cotton under nitrogen atmosphere.

Table 1 Thermogravimetric analysis data of untreated and coated cottons in nitrogen

\begin{tabular}{cccc}
\hline Samples & $\mathrm{T}_{5 \%}\left({ }^{\circ} \mathrm{C}\right)$ & $\mathrm{T}_{\max }\left({ }^{\circ} \mathrm{C}\right)$ & Residue at $700{ }^{\circ} \mathrm{C}(\%)$ \\
\hline Cotton & 310 & 375 & 4.6 \\
Cotton-5BL & 277 & 343 & 31.0 \\
Cotton-10BL & 286 & 333 & 36.1 \\
Cotton-15BL & 242 & 312 & 39.9 \\
\hline
\end{tabular}

The flame retardant properties of the treated cotton fabrics are 45 evaluated by vertical flame tests, and the images during the flammability test were taken, as shown in Fig. 7. After removing the ignition source, the un-coated cotton burns very vigorously and completely consumes at $30 \mathrm{~s}$. With 5 bilayers, the cotton fabric still cannot stop the fire spread and finally the fabric burns 50 to the top. However, the weave structures of the cotton-5BL were well maintained after combustion. $10 \mathrm{BL}$ fabric burns similarly to the fabric coated with $5 \mathrm{BL}$, but the flame propagation rate on the fabric decreases. As for the 15 BL-coated cotton fabric, the flame extinguishes immediately upon removing the ignition source, ${ }_{55}$ leaving behind a small charred area. This phenomenon means that the char formed in cotton-15BL is durable enough to inhibit additional cotton from decomposition and starve the flame of fuel. 


\section{Cite this: DOI: $10.1039 / \mathrm{c0xx00000x}$}
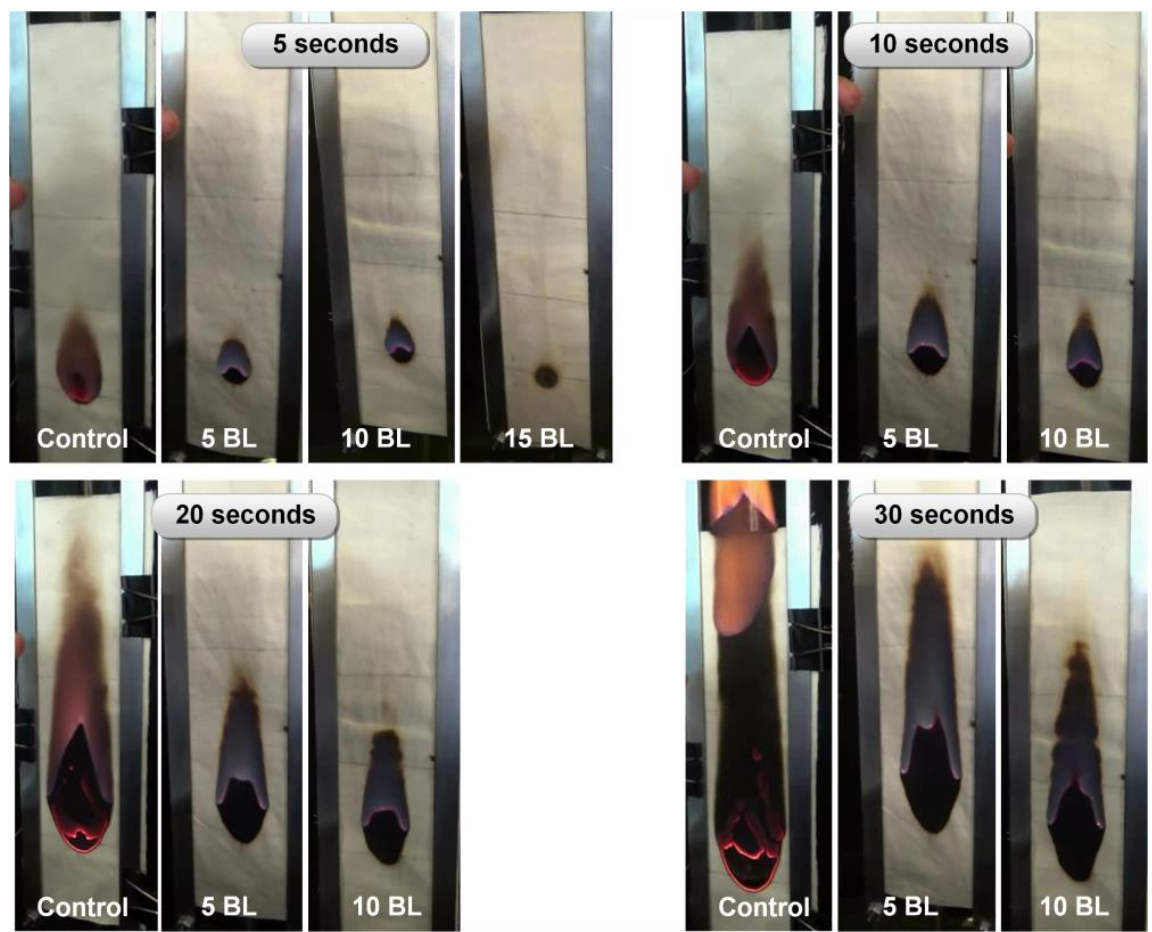

Fig. 7 Snapshots showing vertical flame tests of the control and coated cotton recorded at 5, 10, 20 and $30 \mathrm{~s}$.

SEM images of the post-burn samples after vertical burning tests are shown in Fig. 8. As can be observed, the control sample 5 exhibits a loose and cracked residue after burning, as an indicative of its high flammability. The heat and oxygen could easily penetrate through these holes and gaps so that the control sample burned out. Fibers in the $5 \mathrm{BL}$ fabrics retain their integrity after burning, and fibers with the $10 \mathrm{BL}$ coating also maintain the 10 same shape and size, very similar to the fibers before burning. When the BL number increases to 20 , the morphology of the after-burn cotton seems quite different. The surface of the fibers looks very rough, and there are lots of bubbles on top and in the gap between fibers, which is attributed to swelling and expansion 15 of the coating due to the intumescent effect. The intumescent layer protects the fibers from further burning, preserving woven structure and fiber integrity, which is responsible for the selfextinguishing phenomenon of cotton-15 BL.
Control

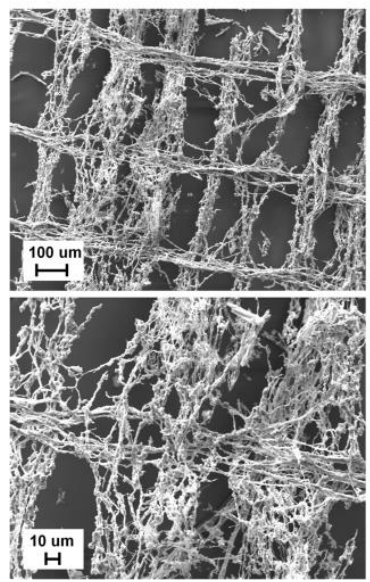

Cotton-5 BL

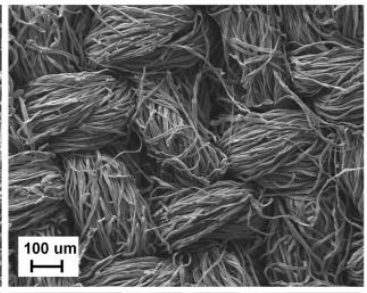

Cotton-10 BL

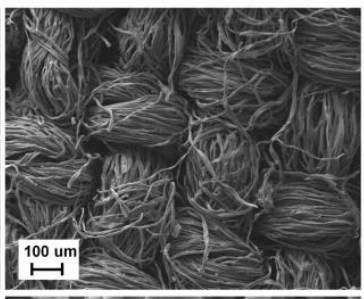

Cotton-15 BL

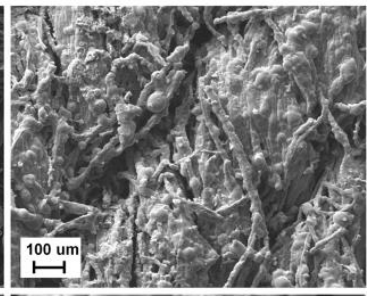

Fig. 8 SEM images of control fabric and fabric coated with 5, 10, and 15 BL of SiN-PA after burning. 


\section{Cite this: DOI: $10.1039 / \mathrm{c0xx00000x}$}

\section{www.rsc.org/xxxxxx}

ARTICLE TYPE

Control, 5, 10, and $15 \mathrm{BL}$ of SiN-PA-coated cotton fabrics were measured with the cone calorimeter for evaluating the flammability behavior. There is a major reduction in peak heat release rate (PHRR) and total heat release (THR) for coated 5 fabrics, as shown in Fig. 9 and Table 2. Comparing the uncoated control to $5 \mathrm{BL}$ of coated cotton fabrics, the PHRR decreases from 186 to $145 \mathrm{~kW} \mathrm{~m}^{-2}$, corresponding to an approximately $22 \%$ reduction. The THR also drops significantly, going from 10.04 down to $7.34 \mathrm{MJ} \mathrm{m}^{-2}$. With the 10 and $15 \mathrm{BL}$ coated fabrics, both 10 the PHRR and the THR further decrease. From Table 2, it can be found that incorporation of SiN-PA has an obvious improvement on the time-to-ignition (TTI) of the coated fabrics, which is probably attributed to that the presence of intumescent coatings delays the release of flammable degradation gaseous products. ${ }_{15}$ Comparing the uncoated control to $5,10,15 \mathrm{BL}$ of coated cotton fabrics, the mean mass loss rate (MLR) is suppressed and, consequently, the residual mass after burning is increased from 8.7 to $28.0,30.5$ and $36.4 \mathrm{wt} \%$, respectively, which is also observed in TGA testing. The improved char yield indicates that 20 more cotton participate in the carbonization process due to the presence of coatings. Therefore, less degradation products that serve as "fuel" go into the gas phase; as a result, the PHRR and THR values are dramatically reduced. The fire growth rate index
(FIGRA) was calculated by the ratio of PHRR and time to PHRR. ${ }_{25}$ The FIGRA value of the control cotton is $2.7 \mathrm{~kW} \mathrm{~m}^{-2} \mathrm{~s}^{-1}$, whereas that for 5, 10, $15 \mathrm{BL}$ coated cotton is $2.1,1.7$ and $1.4 \mathrm{~kW} \mathrm{~m}^{-2} \mathrm{~s}^{-1}$, respectively. The reduced FIGRA value means the suppressed fire spread and possible ignition of the material. ${ }^{18}$

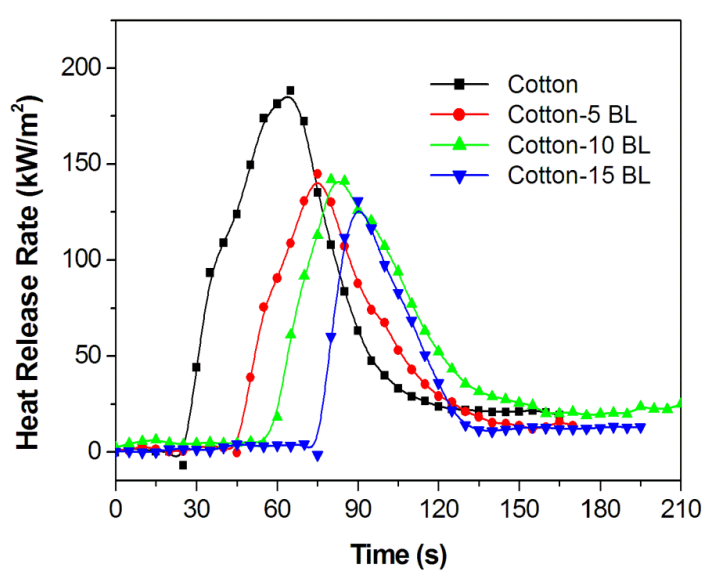

30 Fig. 9 The heat release rate versus time curves of untreated and coated cotton fabrics.

Table 2 Collected data of untreated and coated cotton fabrics by cone calorimetry

\begin{tabular}{|c|c|c|c|c|c|c|c|}
\hline Sample & $\begin{array}{l}\text { TTI } \\
\text { (s) }\end{array}$ & $\begin{array}{c}\text { PHRR }\left(\mathrm{kW} \mathrm{m}^{-2}\right) \\
{[\% \text { Reduction] }}\end{array}$ & $\begin{array}{l}\text { THR }\left(\mathrm{MJ} \mathrm{m}^{-2}\right) \\
\text { [\%Reduction] }\end{array}$ & $\begin{array}{l}\text { Time to PHRR (s) } \\
\text { [\%Increment] }\end{array}$ & $\begin{array}{l}\text { Mean MLR }\left(\mathrm{g} \mathrm{s}^{-1}\right) \\
\text { [\%Reduction] }\end{array}$ & $\begin{array}{l}\text { FIGRA }\left(\mathrm{kW} \mathrm{m}^{-2} \mathrm{~s}^{-}\right. \\
1 \text { ) [\%Reduction] }\end{array}$ & $\begin{array}{l}\text { Residual Mass (wt \%) } \\
\text { [\%Increment] }\end{array}$ \\
\hline Cotton & 26 & $186 \pm 2[-]$ & $10.04 \pm 0.11[-]$ & $68[-]$ & $0.050 \pm 0.001[-]$ & $2.7[-]$ & $8.7 \%[-]$ \\
\hline Cotton-5 BL & 40 & $145 \pm 2[22]$ & $7.34 \pm 0.32[27]$ & $70[3]$ & $0.047 \pm 0.001[6]$ & $2.1[22]$ & $28.0 \%[222]$ \\
\hline Cotton-10 BL & 61 & $138 \pm 2[26]$ & $7.60 \pm 0.43[24]$ & $80[18]$ & $0.041 \pm 0.003[18]$ & $1.7[37]$ & $30.5 \%[250]$ \\
\hline Cotton-15 BL & 77 & $128 \pm 7[31]$ & $6.26 \pm 0.35[38]$ & $90[32]$ & $0.040 \pm 0.003[20]$ & $1.4[48]$ & $36.4 \%[318]$ \\
\hline
\end{tabular}

Note: [\% change] is the percent reduction in a given parameter for coated cotton relative to the control

35 Based upon the fire behavior aforementioned, it is believed that the formation of intumescent char layer is responsible for suppressing fire propagation at this heat flux, or greatly inhibiting the amount of flammable gases available for combustion. In order to prove it, the volatile components of the control and cotton40 15BL are investigated by TG-FTIR technique. The 3D FTIR diagrams of the control and cotton-15BL are displayed in Fig. 10. It can be observed that the deposition of SiN-PA coatings does not alter the position of FTIR bands significantly, suggesting the similar decomposition products of the control and cotton-15BL.

${ }_{45}$ Some of the gaseous degradation products of the cotton are unambiguously identified by the characteristic FTIR signals: the peaks at the wavenumber range of $3450-3600 \mathrm{~cm}^{-1}$ are ascribed to the vibration absorption of hydroxide groups, indicating the release of water vapor; ${ }^{19}$ the peaks at $2876-2982 \mathrm{~cm}^{-1}$ are ascribed 50 to the aliphatic $\mathrm{C}-\mathrm{H}$ bonding deriving from various alkanes; ${ }^{20}$ the sharp peak at $2360 \mathrm{~cm}^{-1}$ is attributed to the absorbance of $\mathrm{CO}_{2},{ }^{21}$ the intense peak at $1740 \mathrm{~cm}^{-1}$ is due to the absorbance of stretching vibration of $\mathrm{C}=\mathrm{O}$ group; ${ }^{22}$ the absorption peak at 1086 $\mathrm{cm}^{-1}$ is owing to the stretching vibration of $\mathrm{C}-\mathrm{O}-\mathrm{C}$ bond from 55 ethers. ${ }^{23}$ 


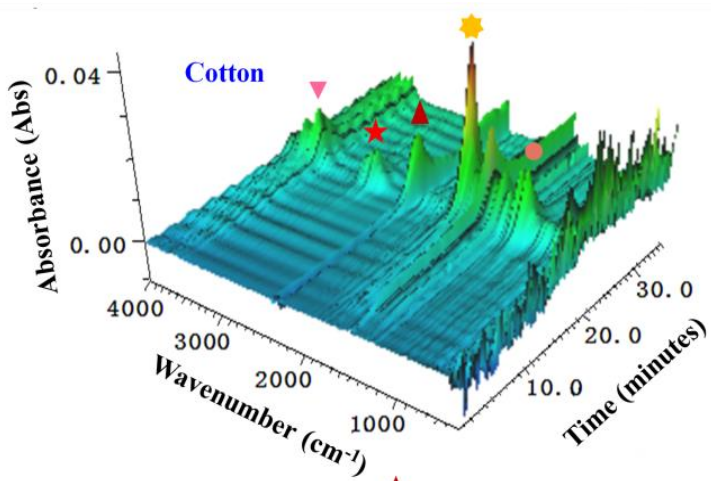

To further understand the mechanism of the suppressed fire 5 hazards by SiN-PA coating, the absorbance of the selected degradation products for the control and cotton-15BL versus temperature is revealed in Fig. 11. As can be seen, the degradation products could be mainly divided into two categories: one is the inflammable gases, such as water vapor and $\mathrm{CO}_{2}$; the 10 other is the flammable gases, such as carbonyl compounds and esters. The maximum absorbance intensity of the inflammable gas products for cotton-15BL is much higher than that for the control, which could dilute the concentration of the flammable gases. Meanwhile, the maximum absorbance intensity of the 15 flammable gas products for cotton-15BL is much lower compared to that for the control. The reduced amount of the carbonyl and ether compounds indicates less "fuel" to be fed back to flame, and thus the reduced heat release rate and total heat release are observed in cone calorimeter testing.

20

25

V $3400-3600 \mathrm{~cm}^{-1}: \mathrm{H}_{2} \mathrm{O} \quad \star 2876-2982 \mathrm{~cm}^{-1}:-\mathrm{CH}_{2}$ - and $-\mathrm{CH}_{3}$

$\triangle 2360 \mathrm{~cm}^{-1}: \mathrm{CO}_{2} \quad 1760 \mathrm{~cm}^{-1}: \mathrm{C}=\mathrm{O} 1086 \mathrm{~cm}^{-1}: \mathrm{C}-\mathrm{O}-\mathrm{C}$

Fig. 10 The 3D diagrams of the gaseous volatiles during decomposition process of the control and cotton-15BL.
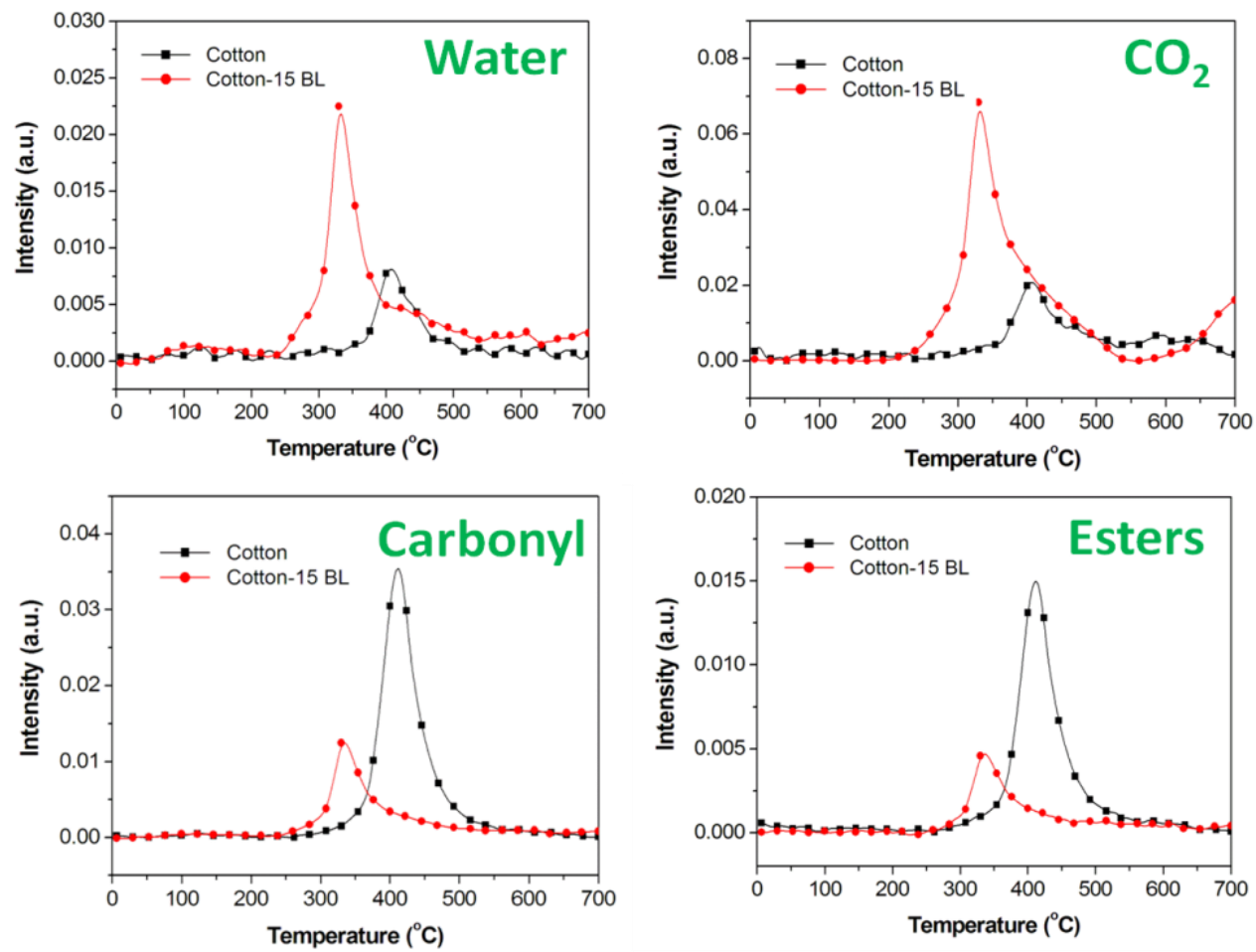

Fig. 11 Intensity of characteristic peaks for pyrolysis products of the control and cotton-15BL.

It is clear that the use of intumescent coating significantly reduces the flammability of cotton fabric under a $35 \mathrm{~kW} \mathrm{~m}^{-2}$ heat flux. In this coating formulation, the phosphorus and nitrogen 35 species catalyze the formation of the char layer, and thereby less 
flammable gases degraded from cotton feed back to flame as "fuel"; meanwhile, the presence of silicon element is beneficial to that the chars formed here are thermally stable enough that a heat flux of $35 \mathrm{~kW} \mathrm{~m}{ }^{-2}$ cannot maintain fire spread.

\section{${ }_{5}$ Conclusion}

In conclusion, an intumescent coating composed of nitrogenmodified silane hybrid and phytic acid was successfully deposited on cotton fabric through the combination of sol-gel process and layer-by-layer techniques. By applying this intumescent coating 10 on cotton fabric, flame was immediately extinguished on fabric coated with 15 BL of SiN-PA. Post-burn chars were observed with SEM and the images showed that the weave structure, and fiber shape and structure, were well preserved after coating SiNPA. Especially for the $15 \mathrm{BL}$ char, bubbles were formed on the 15 surface of the fibers during burning due to an intumescent effect. From cone calorimetry data, the peak heat release rate and total heat release of 15 BL-coated fabric exhibited a $31 \%$ and $38 \%$ reduction compared to the control fabric. The enhanced fire resistance by the presence of the intumescent coating was mainly 20 attributed to two key factors: for one thing, the amount of flammable gases was reduced while that of inflammable gases was increased, which cannot support the fire propagation; for another, the chars formed were thermally stable enough to shield the underlying materials from ignition. This study demonstrates

25 the combination of layer-by-layer assembly and sol-gel method opens an effective and environmentally friendly route to current flame-retardant treatments.

\section{Acknowledgements}

The authors want to acknowledge "AMAROUT II EUROPE" 30 Marie Curie COFUND action, partially funded by the European Union's 7th Framework Programme under Grant Agreement $n^{\circ}$ 291803. Also, this work is partly funded by the European Project COST Action MP1105 "FLARETEX", and Ramón y Cajal grant (RYC-2012-10737).

\section{${ }_{35}$ Notes and references}

${ }^{a}$ Madrid Institute for Advanced Studies of Materials (IMDEA Materials), C/Eric Kandel, 2, 28906 Getafe, Madrid, Spain. E-mail: deyi.wang@imdea.org; Fax: +34 915503047; Tel.: +34 915493422-1055. ${ }^{b}$ School of Aeronautics and Space Engineering, Universidad Politécnica 40 de Madrid, 28040 Madrid, Spain

${ }^{c}$ Beijing Key Laboratory of Clothing Materials $R \& D$ and Assessment, School of Materials Science \& Engineering, Beijing Institute of Fashion Technology, Beijing 100029, P. R. China

451 Y. C. Li, S. Mannen, A. B. Morgan, S. Chang, Y. H. Yang, B. Condon and J. C. Grunlan, Adv. Mater., 2011, 23, 3926.

2 G. Laufer, C. Kirkland, A. B. Morgan and J. C. Grunlan, Biomacromolecules, 2012, 13, 2843.

3 L. Yu, S. Zhang, W. Liu, X. Zhu, X. Chen and X. Chen, Polym. 50 Degrad. Stabil., 2010, 95, 1934.

4 E. Kandare, A. K. Chukwunonso and B. K. Kandola, Fire Mater., $2011,35,143$.

5 M. Tsafack and J. Levalois-Grützmacher, Surf. Coat. Technol., 2006, 200, 3503.

556 H. Yang and C. Q. Yang, J. Fire Sci., 2007, 25, 425.

7 F. Carosio, G. Laufer, J. Alongi, G. Camino and J. C. Grunlan, Polym. Degrad. Stabil., 2011, 96, 745.
8 J. Alongi, F. Carosio and G. Malucelli, Polym. Degrad. Stabil., 2012, 97, 1644 .

609 K. Apaydin, A. Laachachi, V. Ball, M. Jimenez, S. Bourbigot, V. Toniazzo and D. Ruch, Polym. Degrad. Stabil., 2013, 98, 627.

10 Y. C. Li, Y. S. Kim, J. Shields and R. Davis, J. Mater. Chem. A, 2013, 1, 12987.

11 G. Laufer, C. Kirkland, A. B. Morgan and J. C. Grunlan, ACS Macro Lett., 2013, 2, 361.

12 J. Alongi, M. Ciobanu and G. Malucelli, Carbohyd. Polym., 2011, 85, 599.

13 G. Brancatelli, C. Colleoni, M. R. Massafra and G. Rosace, Polym. Degrad. Stabil., 2011, 96, 483.

7014 E. Devaux, M. Rochery and S. Bourbigot, Fire Mater., 2002, 26, 149.

15 C. F. Kuan, W. J. Chen, Y. L. Li, C. H. Chen, H. C. Kuan and C. L. Chiang, J. Phys. Chem. Solids, 2010, 71, 539.

16 F. Shafizadeh, A. G. Bradbury, W. F. DeGroot and T. W. Aanerud, Ind. Eng. Chem. Prod. Res. Dev., 1982, 27, 97

7517 M. Espinosa, M. Galia and V. Cadiz, J. Polym. Sci. Part A: Polym. Chem., 2004, 42, 3516.

18 B. Biswas and B. K. Kandola, Polym. Adv. Technol., 2011, 22, 1192.

19 N. Huang and J. Wang, J. Anal. Appl. Pyrolysis, 2009, 84, 124.

20 Y. Y. Dong, Z. Gui, Y. Hu, Y. Wu and S. H. Jiang, J. Hazard. Mater., 2012, 209, 34

21 S. Gaan, P. Rupper, V. Salimova, M. Heuberger, S. Rabe and F. Vogel, Polym. Degrad. Stabil., 2009, 94, 1125.

22 X. L. Chen, L. Huo, C. M. Jiao and S. Li, J. Anal. Appl. Pyrolysis, 2013, 100, 186.

8523 B. Ghosh, K. V. Chellappan and M. W. Urban, J. Mater. Chem., 2011, 21, 14473. 